\title{
Growth and competition among understory plants varies with reclamation soil and fertilization
}

\author{
Jennifer Buss, Kyle Stratechuk and Bradley D. Pinno * (D)
}

\begin{abstract}
Introduction: Following oil sands mining in Alberta, Canada, the main land management goal is to establish a functioning boreal forest ecosystem, including the understory plant community. One of the challenges with restoring the understory is the presence of non-native species that compete with desirable native species for resources. In a greenhouse experiment, we studied the growth of two native understory species (Galium boreale and Vicia americana) and a non-native invasive species (Matricaria perforata) grown with either intra- or interspecific neighbors across three common land reclamation soils and a nitrogen fertilizer treatment.

Results: When grown by itself, $V$. americana aboveground biomass did not differ among soil or fertilizer treatments, likely due to its ability to fix nitrogen. Growth of $M$. perforata was directly related to soil nitrogen, and it had the greatest increase in biomass with fertilization. Growth and biomass of $G$. boreale was less than the other species, and it had the highest mortality in the nitrogen-poor soil. When grown together, the proportional biomass of M. perforata and $V$. americana varied with soil treatment such that $M$. perforata was dominant in the high-nitrogen forest floormineral mix treatment while $V$. americana was dominant in the low-nitrogen peat-mineral mix.
\end{abstract}

Conclusions: Operationally, care should be taken when applying fertilizer to reclamation areas, as it may have an unwanted positive effect on growth for undesirable non-native plants at the expense of native species. In terms of seed mixtures, $V$. americana may be a good option for low inorganic nitrogen resource soils and $G$. boreale for high nitrogen resource soils.

Keywords: Matricaria perforata, Galium boreale, Vicia americana, Forest floor-mineral mix, Peat-mineral mix, Oil sands reclamation

\section{Introduction}

Plant growth varies with the availability of resources, i.e. light, water, and nutrients, in particular nitrogen (Canham et al. 1996). In the natural environment, these resources do not have the same availability and can vary across regions and soil types (Chapin et al. 1987). Resource availability also plays a role in the outcome of competition between plants as it differentially impacts productivity (Fridley 2002). However, there is some debate over whether competition is more likely to occur when resources are highly available or when they are scarce. When resources are less abundant, plant

\footnotetext{
* Correspondence: bpinno@ualberta.ca

Department of Renewable Resources, University of Alberta, Edmonton, Alberta, Canada
}

competition could be higher due to limited resources and differences in utilization efficiency among species (Damgaard and Weiner 2017). An opposing hypothesis is that competition increases with resource availability because of higher biomass, growth rates, and shading that occur (Pyšek and Leps 1991; Wilson and Tilman 1991). The outcome may also depend on the specific plant species, with some species being stronger competitors under high-resource conditions while others may be more successful under low resource availability. For example, in a nutrient-rich environment, a species that is able to grow faster would have the competitive advantage (Aerts 1999, DeMalach et al. 2016) while on a nutrient-limited site, a species with higher nutrient utilization efficiency, instead of faster growth, may have the competitive advantage (Aerts 1999). 
The competitive ability of a species is likely to vary on land reclamation sites by soil type and reclamation treatments due to differences in nutrient availability (Sloan and Jacobs 2013). In general, there are two main types of reclamation cover soils currently used in oil sands mine reclamation in Northern Alberta, Canada: forest floormineral mix (FFMM) and peat-mineral mix (PMM). FFMM is an upland boreal forest soil, composed of the organic forest floor layer and underlying mineral soil that is salvaged prior to mining. PMM is mainly composed of lowland peat, which is in high abundance in the oil sands region, and underlying mineral soil. PMM has a high water holding capacity that has been shown to increase tree seedling establishment (Pinno and Errington 2015). If used immediately following salvage, both soil types contain native plant propagules that can aid in the restoration of boreal forest ecosystems (Schott et al. 2016). The difference in nutrient profiles for these two reclamation soils has important implications for plant growth and development. FFMM has lower C:N ratios with higher nitrogen mineralization and inorganic nitrogen supply rates compared to PMM, resulting in greater vegetation cover and plant growth on the FFMM (Kwak et al. 2016). Despite FFMM's greater inorganic nitrogen availability and initial plant growth, it cannot be used in place of PMM consistently because there is a limited availability within the region.

To make up for differences across reclamation soil treatments, fertilizer is often used to augment nutrient levels and allow for a larger plant abundance and richness to be supported in less fertile soil (Sloan and Jacobs 2013). However, an undesired effect can occur, where a fertilizer can increase competition between desirable and weedy plant species (Pyšek and Leps 1991). In some cases, fertilization has led to declines in species richness on a site, specifically native species, due to suppression of native forbs from an increase in non-native species cover (Buckley and Catford 2016; Huenneke et al. 1990). Non-native species are of concern on reclamation sites since they are initially unoccupied. This results in a low competition environment that gives non-native species the opportunity to colonize and rapidly spread, thereby potentially preventing the growth and establishment of tree seedlings or other native species on reclaimed mine sites (Franklin et al. 2012).

In the mineable oil sands region, Vicia americana and Galium boreale are two native forb species of interest to reclamation practitioners given that they are both adapted to growing in a variety of soil conditions, are drought tolerant, and can reproduce by seeds and rhizomes resulting in faster plant establishment, site occupation, and soil stabilization (McLean 1969). $V$. americana is also a nitrogen-fixing legume which may allow it to grow well on nutrient-poor soils or facilitate the growth of other species as has been found for other vetch species (Paul et al. 1971; Tosti et al. 2010). Matricaria perforata is an introduced weedy species that reproduces by seed and can survive in a variety of different climates and site types, especially those that are heavily disturbed such as new reclamation areas (Woo et al. 1991). Fertilization could potentially facilitate invasion by $M$. perforata and contribute to its success on a site due to its strong positive growth response to nitrogen availability (Kim et al. 2006).

In this greenhouse study, we examine how reclamation soil type and fertilizer application impact the growth and competitive ability of three important understory plant species, native forbs $G$. boreale and $V$. americana and non-native forb $M$. perforata, grown with either intraor interspecific neighbours. Our hypothesis is that plants will grow better in FFMM and with fertilization because of the increased resource availability. In terms of competitive interactions, we hypothesize that competition will vary among soil types and fertilization treatments with higher resource availability favouring the nonnative $M$. perforata.

\section{Methods}

We used a completely randomized design with seven vegetation treatments, three soil types, two fertilizer treatments, and six replicates for a total of 252 pots in our greenhouse experiment. The three plant species used in this experiment were G. boreale (northern bedstraw, native forb), $V$. americana (American vetch, native forb), and $M$. perforata (scentless chamomile, non-native forb). The seven vegetation treatments were pure pots, i.e. monocultures of each plant species, mixed pots of each species pair (three species pair combinations), and control pots with no plants. Seedlings were planted at a density of four plants per pot in either pure or mixed (2:2) combinations.

The three soil treatments were FFMM, PMM, and a layered soil. The layered soil was comprised of 1/3 FFMM and 2/3 PMM, with the FFMM placed on the top. All soils used were taken from operational stockpiles in the oil sands region and reflect typical stockpiled reclamation soil. Soils were sieved using a $1-\mathrm{cm}^{2}$ mesh before being placed into pots $(V=2.83 \mathrm{~L}, d=15 \mathrm{~cm}, h=16 \mathrm{~cm})$. The bottom half of each pot $(6.5 \mathrm{~cm})$ was filled with sand and the top half $(7.5 \mathrm{~cm})$ with one of the soil treatments. For the layered soil treatment pots, roughly $5 \mathrm{~cm}$ of PMM and $2.5 \mathrm{~cm}$ of FFMM were added to each pot. Half of the pots received immediately available fertilizer in solution once a week for 4 weeks using a 30-10-10NPK fertilizer at a rate equivalent to a total of $100 \mathrm{~kg} \mathrm{~N} / \mathrm{ha}$.

Seedlings were grown in small plugs $(2 \mathrm{~cm} \times 2 \mathrm{~cm})$ with a peat potting mixture (Premier Sphagnum Peat 
Moss) until transplanting into larger pots. G. boreale was seeded 5 weeks before transplanting, $M$. perforata 4 weeks before transplant, and $V$. americana 3 weeks before. Species were planted in this order, so they would be of similar size before planting and large enough to survive the transplant. Plugs were covered with plastic wrap until germination began and watered one to two times daily until transplanting. When seedlings were transplanted from the plugs into the treatment pots, their roots were washed to remove any residual peat and to directly expose the plants to the soil treatment. The pots were then placed in a greenhouse under an 18-h light and 6-h dark photoperiod with day and night temperatures of 24 and $19{ }^{\circ} \mathrm{C}$. Relative humidity was constant at approximately $60 \%$. At the time of transplanting, the average height of $G$. boreale was $1.17 \mathrm{~cm}, M$. perforata was $1.55 \mathrm{~cm}$, and $V$. americana was $6.38 \mathrm{~cm}$.

All pots were watered to field capacity daily for 3 weeks after transplanting, and then the regular watering and fertilization treatments were applied. Thereafter, all pots were watered twice weekly with $336 \mathrm{~mL}$ of water per pot. This watering approach, as opposed to daily watering to field capacity, was done to emulate water-stressed field conditions.

Soil $\mathrm{pH}$ and electrical conductivity (EC) were measured on all control pots from samples taken at the time the pots were filled. For the layered pots, a small sample from each layer was taken. Measurements were taken using a VMR symPHony handheld meter. Volumetric water content was measured in all pots immediately before harvest, 4 days after the last watering treatment, using a time-domain reflectometer (TDR; 100 field scout), to a depth of $7.6 \mathrm{~cm}$. To determine an index of water use, volumetric water content of treatment pots was subtracted from the water content of control pots and then converted to a change in soil water content per gram of plant biomass basis.

Plant root simulator probes (PRS probes; Western Ag Innovations, Saskatoon, SK, Canada) were used to measure nutrient supply rates in half of the treatment pots and all the control pots. In the control pots, a complete nutrient analysis was done, and in the treatment pots, only nitrate $\left(\mathrm{NO}_{3}{ }^{-}\right)$and ammonium $\left(\mathrm{NH}_{4}{ }^{+}\right)$were measured. A single pair of anion and cation probes were installed after fertilization, removed after 35 days, rinsed with deionized water, and sent to Western Ag Innovations for analysis. All nutrients $(\mathrm{Ca}, \mathrm{Mg}, \mathrm{K}, \mathrm{P}, \mathrm{Fe}, \mathrm{Mn}$, $\mathrm{Cu}, \mathrm{Zn}, \mathrm{B}, \mathrm{S}, \mathrm{Pb}, \mathrm{Al}$, and $\mathrm{Cd}$ ), except $\mathrm{NH}_{4}{ }^{+}$and $\mathrm{NO}_{3}{ }^{-}$, were quantified using inductively coupled plasma spectroscopy. $\mathrm{NH}_{4}{ }^{+}$and $\mathrm{NO}_{3}{ }^{-}$supply rates were quantified colorimetrically with an automated flow injection analysis system. An index of inorganic nitrogen use was calculated by subtracting total inorganic nitrogen in the treatment pots from the control pots and then converting this to a nitrogen use per gram of plant biomass basis.

Individual plants were harvested 10 weeks after the first fertilizer application (13 weeks after transplanting) and dried to a constant weight at $35{ }^{\circ} \mathrm{C}$. Roots of all pure species pots were separated from the soil by hand, washed with tap water until clean, and dried until a constant weight was reached. $M$. perforata flowered frequently during the experiment (13 weeks) so the presence of flowers was noted, and the flowers were clipped to include in the biomass measurements. Mortality was also noted for all species.

All statistical analyses were done using $\mathrm{R}$ (version 3.4.0). Given the differences in starting height among species, an ANCOVA was used to determine the effect of initial height on aboveground and belowground biomass, with initial height being a covariate. However, initial height was not a significant effect in the model, and therefore, ANOVAs were used to compare responses among treatments. Multi-factor ANOVAs were used to compare above- and belowground biomass for all species separately, across different soil and fertilizer treatments. Pairwise analysis (Tukey's HSD $\alpha<0.05$ ) was used to determine the effect of soil type and fertilization on the aboveground and belowground biomass in pure pots for each species individually and in the mixed species pots. A chi-squared test was used to test mortality in G. boreale and flowering in $M$. perforata across different soil, fertilization, and competition treatments.

\section{Results}

The three soil types differed significantly in terms of $\mathrm{pH}$, inorganic nitrogen, sulfur, and magnesium, with $\mathrm{pH}$ being highest in the FFMM, lowest in the PMM, and intermediate in the layered soil type (Table $1, p<0.001$ for all comparisons). Inorganic nitrogen was greater in FFMM compared to the layered soil $(p=0.006)$ and PMM $(p<0.001)$, while there was no difference between the layered and PMM soil types $(p>0.05)$. Fertilization increased inorganic nitrogen in all soils $(p<0.001)$ but did not impact other nutrients $(p>0.05)$.

Overall, the aboveground biomass in pure pots across all treatments ranged from an average of $0.300 \mathrm{~g}$ in $G$. boreale and $0.585 \mathrm{~g}$ in M. perforata to a high of $0.763 \mathrm{~g}$ in $V$. americana (Fig. 1, Table 1). V. americana aboveground biomass did not differ among soil or fertilizer treatments (Table 2). However, both M. perforata and G. boreale responded to soil and fertilization treatments, with a lower biomass in PMM and higher biomass in FFMM and layered soil (Fig. 1, Table 2). Both species also exhibited a positive growth response to fertilization across all soil types (Table 2). M. perforata had the 
Table 1 Soil properties of control pots (i.e. with no plants). Values are means and standard error

\begin{tabular}{|c|c|c|c|c|c|c|}
\hline & $\mathrm{pH}$ & EC $\left(d s^{*} m^{-1}\right)$ & VWC (\%) & $\mathrm{N}\left(\mu \mathrm{g}^{*} 10 \mathrm{~cm}^{-2 *} 35\right.$ days $\left.^{-1}\right)$ & $\mathrm{P}\left(\mu \mathrm{g}^{*} 10 \mathrm{~cm}^{-2 *} 35\right.$ days $\left.^{-1}\right)$ & $\mathrm{K}\left(\mu \mathrm{g}^{*} 10 \mathrm{~cm}^{-2 *} 35\right.$ days $\left.^{-1}\right)$ \\
\hline \multicolumn{7}{|l|}{ FFMM } \\
\hline No fertilizer & $5.98(0.02)$ & $0.13(0.006)$ & $39.9(2.5)$ & $494.4(25.8)$ & $0.68(0.26)$ & $24.0(1.8)$ \\
\hline Fertilizer & $5.90(0.06)$ & $0.12(0.004)$ & $50.2(1.8)$ & $788.6(36.6)$ & $0.86(0.37)$ & $24.9(1.1)$ \\
\hline \multicolumn{7}{|l|}{ Layered } \\
\hline No fertilizer & $4.98(0.2)$ & $0.09(0.01)$ & $36.2(4.3)$ & $262.1(30.4)$ & $0.78(0.17)$ & $21.2(2.5)$ \\
\hline Fertilizer & $4.50(0.1)$ & $0.14(0.02)$ & $44.5(2.4)$ & $640.4(44.0)$ & $0.77(0.17)$ & $19.3(1.3)$ \\
\hline \multicolumn{7}{|l|}{ PMM } \\
\hline No fertilizer & $4.22(0.05)$ & $0.2(0.02)$ & $33.3(1.7)$ & $85.2(18.1)$ & $0.86(0.17)$ & $15.7(2.9)$ \\
\hline Fertilizer & $4.17(0.03)$ & $0.2(0.01)$ & $37.2(1.7)$ & $399.9(23.4)$ & $0.78(0.15)$ & $24.1(2.6)$ \\
\hline
\end{tabular}

Note: VWC is volumetric water content, EC is electrical conductivity, FFMM is forest floor-mineral mix, and PMM is peat-mineral mix. $\mathrm{N}$ is the total inorganic nitrogen (including both nitrate and ammonium) supply rate, $\mathrm{P}$ is the phosphorus supply rate, and $\mathrm{K}$ is the potassium supply rate

greatest absolute biomass increase due to fertilization (average increase $=0.320 \mathrm{~g}, p<0.001$ ) compared to $G$. boreale $(0.172 \mathrm{~g}, p=0.011)$ and $V$. americana $(0.003 \mathrm{~g}$, $p=0.965)$.

The response of belowground biomass in pure pots differed from aboveground biomass in that $V$. americana had higher belowground biomass in the layered soil than the PMM (Fig. 2), and fertilizer decreased belowground biomass (Table 2). G. boreale belowground biomass, however, did not differ between fertilizer treatments (Table 2) but was higher for the layered soil than for the FFMM (Fig. 2). Similar to $V$. americana, $M$. perforata belowground biomass had a negative response to fertilizer (Table 2) and was lower in PMM than in FFMM (Fig. 2).

Water use index, i.e. the difference in soil water content between controls and planted pots standardized by plant biomass (\% water content/g plant biomass), was greatest for $V$. americana (average $=34.7$ ) when compared to $M$. perforata (average $=11.2, p=0.016$ ), with $G$. boreale water use (average $=28.5$ ) being no different than $V$. americana $(p=0.743)$ or $M$. perforata $(p=0.100)$. Inorganic nitrogen use index, on the other hand, was significantly lower in $V$. americana (average $=449.5$ ) than in $G$. boreale (average $=623.3, p=0.029$ ), with $M$. perforata (average $=598.5$ ) having an intermediate inorganic nitrogen index, and no difference between $V$. americana $(p=0.604)$ or $G$. boreale $(p=0.212)$.

When grown in mixed-species pots, G. boreale only made up a small proportion of total pot biomass, with a maximum of $11.0 \%$ of the total pot biomass in the FFMM soil when grown with $V$. americana and a minimum of $2 \%$ when grown with $M$. perforata in the layered soil type. Any differences in G. boreale aboveground biomass when grown with $V$. americana or $M$. perforata were not significant $(p=0.909)$.

When $V$. americana and $M$. perforata were grown together, the relative proportion of aboveground biomass of each species varied with soil type. $V$. americana biomass made up a lower percentage of total pot biomass in the layered and FFMM soil types (35.9 and 20.1\% respectively) when compared with the PMM soil (76.9\%, Fig. 3). The opposite trend was found for $M$. perforata when grown with $V$. americana, with a higher $M$.

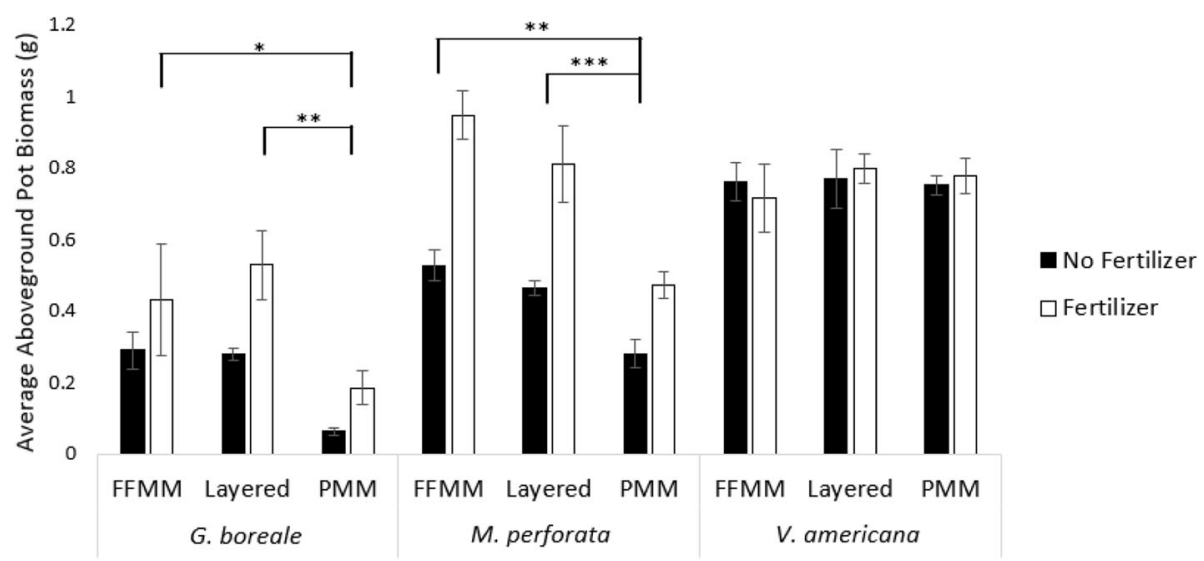

Fig. 1 Average aboveground plant biomass per pot for pure species pots across fertilizer and soil treatments. Bars indicate standard error, and asterisks represent $p$ values generated from post hoc analysis (Tukey's test) that compares subset species across soil treatments $\left({ }^{* * *} p<0.001,{ }^{* *} p<0.01,{ }^{*} p<0.05\right.$ ) 
Table 2 ANOVA table of $F$ and $p$ values on the effects of soil and fertilizer on above- and belowground biomass for different species. Species were subset before the ANOVA was performed

\begin{tabular}{|c|c|c|c|c|c|c|c|c|c|}
\hline & \multicolumn{3}{|c|}{ Vicia americana } & \multicolumn{3}{|c|}{ Matricaria perforata } & \multicolumn{3}{|c|}{ Galium boreale } \\
\hline & $\overline{\mathrm{df}}$ & $F$ & $p$ & $\overline{\mathrm{df}}$ & $F$ & $p$ & $\overline{d f}$ & $F$ & $p$ \\
\hline \multicolumn{10}{|c|}{ Aboveground biomass } \\
\hline Soil & 2.000 & 0.241 & 0.787 & 2.000 & 19.779 & $<0.001$ & 2.000 & 6.939 & 0.003 \\
\hline Fertilizer & 1.000 & 0.003 & 0.956 & 1.000 & 43.618 & $<0.001$ & 1.000 & 6.782 & 0.014 \\
\hline Soil/fertilizer & 2.000 & 0.222 & 0.802 & 2.000 & 1.948 & 0.160 & 2.000 & 0.374 & 0.691 \\
\hline Error & 30.000 & & & 30.000 & & & 30.000 & & \\
\hline \multicolumn{10}{|c|}{ Belowground biomass } \\
\hline Soil & 2.000 & 8.202 & 0.001 & 2.000 & 8.305 & 0.001 & 2.000 & 5.488 & 0.009 \\
\hline Fertilizer & 1.000 & 5.580 & 0.020 & 1.000 & 4.485 & 0.040 & 1.000 & 0.539 & 0.468 \\
\hline Soil/fertilizer & 2.000 & 0.164 & 0.850 & 2.000 & 2.404 & 0.108 & 2.000 & 0.566 & 0.574 \\
\hline Error & 30.000 & & & 29.000 & & & 30.000 & & \\
\hline
\end{tabular}

perforata proportion of biomass in FFMM than in PMM (Fig. 3). Fertilizer did not influence this relationship, as neither $V$. americana nor $M$. perforata aboveground biomass differed with fertilizer when grown together ( $V$. americana $p=0.779, M$. perforata $p=0.121$ ).

Cumulative mortality by the end of the study was highest for G. boreale (17.0\%) and was negligible for $M$. perforata $(0.02 \%)$ and $V$. americana (0\%). Mortality of $G$. boreale was higher in the PMM soil (average $=30.2 \%$ ) and lower in the FFMM $(6.3 \%)(p<0.001)$ and increased in mixed-species pots when grown with $M$. perforata $(p<$ $0.001)$ and $V$. americana $(p=0.006)$ (Fig. 4). Fertilization had no impact on $G$. boreale mortality $(p=0.531)$. The incidence of flowering of $M$. perforata was greater in FFMM (30.2\% of plants flowered) than in PMM $(1.0 \%)(p<0.001)$ but was not impacted by fertilization $(p=0.857)$.

\section{Discussion}

For the three species tested in this study, two of them (G. boreale and $M$. perforata) had greater aboveground biomass in the higher fertility FFMM soil and increased biomass with fertilizer, while the other species (N-fixing $V$. americana) responded to neither soil type nor fertilization. When grown together, $V$. americana and $M$. perforata competitive ability varied by soil type with the lower resource PMM favouring the native species $V$. americana, while the higher resource FFMM favoured the non-native $M$. perforata.

The positive response of $M$. perforata and $G$. boreale to the FFMM, layered soil, and fertilizer, and the negative mortality and flowering responses to PMM, likely indicates a higher inorganic nitrogen demand for these species. One of the main differences in resources among

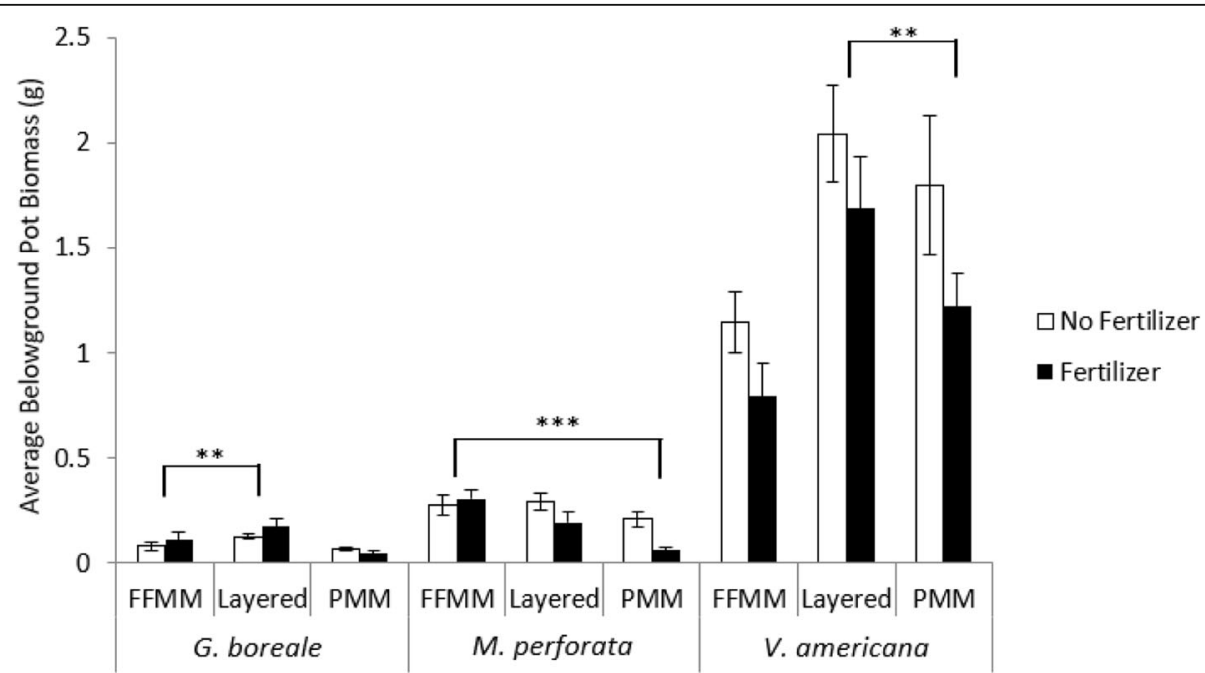

Fig. 2 Average belowground biomass per pot for pure species pots across both fertilizer treatments and the three soil types (forest floor-mineral mix, layered, and peat-mineral mix). Bars indicate standard error, and asterisks represent $p$ values generated from post hoc analysis (Tukey's test) that compares subset species across soil treatments $\left({ }^{* *} p<0.001,{ }^{* *} p<0.01,{ }^{*} p<0.05\right.$ ) 


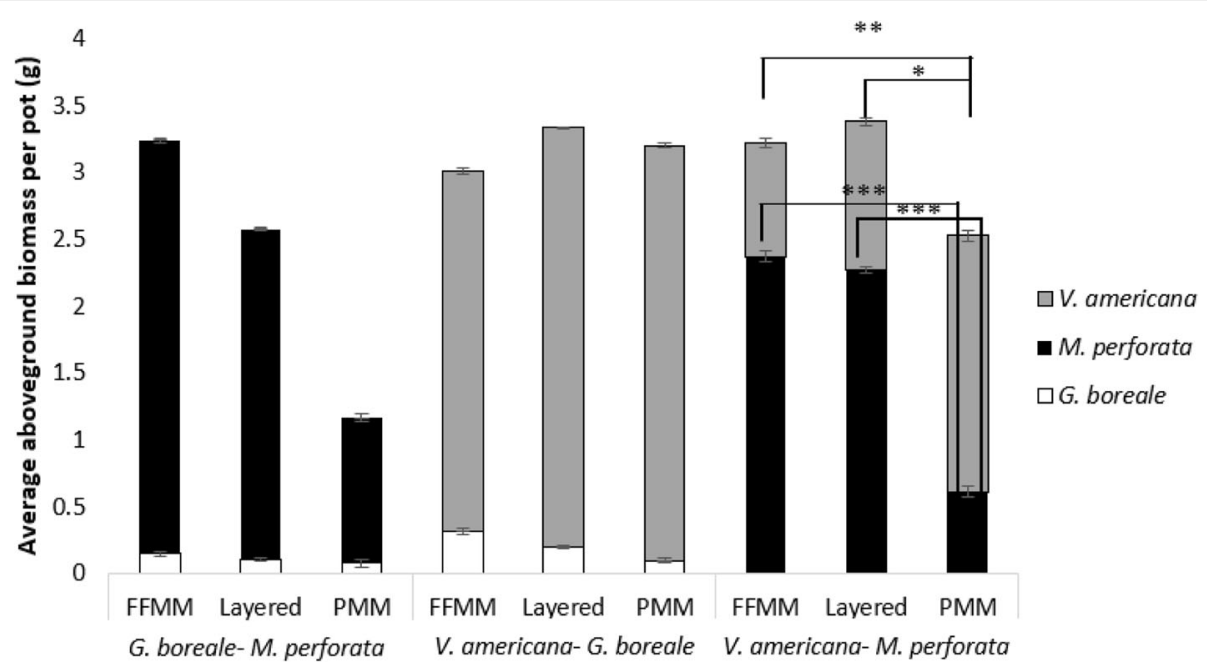

Fig. 3 Average aboveground plant biomass per pot for all competition pot plant species combinations in forest floor-mineral mix, layered, and peat-mineral mix soil types. Bars indicate standard error for each species individually, and asterisks represent $p$ values generated from post hoc analysis (Tukey's test) that compares subset species across soil treatments $\left({ }^{* * *} p<0.001,{ }^{* *} p<0.01,{ }^{*} p<0.05\right.$ )

treatments was the inorganic nitrogen availability, with PMM having the lowest, FFMM having the highest, and fertilization increasing availability for all soils. These differences in nutrient availability between reclamation cover soils have been found in other studies (Duan et al. 2015; Kwak et al. 2016; Pinno et al. 2013). Outside of a greenhouse setting, both $M$. perforata and G. boreale are sensitive to reduced inorganic nitrogen availabilities (Kim et al. 2006; Staples et al. 1999). V. americana, on the other hand, had a very different above- and belowground growth response with no difference in aboveground biomass between soil and fertilizer treatments but with differences in belowground biomass. The highest root biomass was found in the lowest resource PMM soils, a common response to low resource availability in

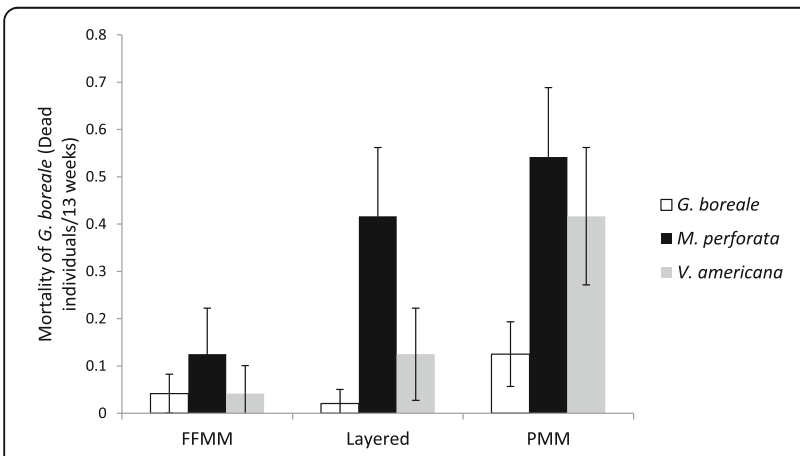

Fig. 4 Mortality of $G$. boreale across soil treatments (forest floor-mineral mix, layered, and peat-mineral mix) and competition with other species over 13 weeks. The different plant species represent the plants that were competing with $\mathrm{G}$. boreale in competition pots. All bars represent G. boreale mortality. Error bars indicate standard error for each species individually legumes (Rochester et al. 1998). The fact that $V$. americana aboveground biomass did not change among soil type indicates that its aboveground growth may have been limited by something other than inorganic nitrogen, which is logical considering it is a nitrogen fixer. Water availability, which was restricted and held constant across all treatments, could be the limiting resource for $V$. americana, as is common in vetch species (Gallacher and Sprent 1978; Haffani et al. 2014). In our study, $V$. americana also had the highest per gram water use, further supporting the importance of water availability for $V$. americana growth.

The layered soil type in our study had a comparable biomass response to FFMM in most scenarios, similar to other studies where layered reclamation soils tended to have intermediate levels of inorganic nitrogen, resulting in an intermediate plant growth response (McMillan et al. 2007). Layering may also be a viable reclamation soil option because it concentrates the seed bank present in the FFMM to the surface layer rather than burying seeds and propagules at depth (MacKenzie and Quideau 2011). Layering also creates a break in the soil column which can result in a greater water holding capacity, an important factor in drier climates such as in northern Alberta (Li et al. 2014; Zettl et al. 2011).

Fertilizer can increase the growth of all plants, but within the confines of this experiment, $M$. perforata had the largest increase in aboveground biomass in response to fertilization of any species. Thus, fertilization may be more advantageous for invasive species, such as $M$. perforata, with highly responsive growth patterns at the expense of more desirable native species that are not as able to immediately respond to increased resource 
availability. Other studies have also found that fertilizer increased grass cover on FFMM (Schott et al. 2016) and the cover of non-native species (Errington and Pinno 2016), making it harder for other vegetation to establish. In extreme cases, an understory could be irreversibly dominated by undesirable non-native species which has been shown to happen with repeated fertilizer application in prairie restoration applications (Wilson and Pinno 2013). However, M. perforata may be less of a concern on nitrogen-poor sites because it is sensitive to reduced resource availability and is therefore a poorer competitor on these sites (Woo et al. 1991). The decreased aboveground biomass response in the nitrogen-poor PMM and the proportion of biomass when grown with $V$. americana on PMM demonstrate this trend for M. perforata.

The competitive balance between $V$. americana and $M$. perforata varied depending on soil type, with $V$. americana dominating in PMM and M. perforata dominating in FFMM. This shifting dominance highlights the differing demands of the two species. Since $V$. americana is a nitrogen fixer, it is most likely not nitrogen limited and is able to grow well in low-nitrogen PMM, while $M$. perforata, a non-nitrogen fixer, with known limitations in low-nitrogen environments, is not. It is possible that these two species are competing for resources besides nutrients, since fertilizer is not having an impact on either species when grown together. For example, as discussed earlier, $V$. americana has a higher water use, when compared to $M$. perforata. $V$. americana could be taking up most of the water and hindering $M$. perforata growth in the PMM. The strong competitive interaction between nitrogen-fixing $V$. americana and non-nitrogen-fixing M. perforata demonstrates that legumes are not always facilitative, and the nitrogen fixed by these species does not always become available in the short term (Kurdali et al. 1996).

Interspecific competition between G. boreale and the other two species led to a higher G. boreale mortality, particularly on the nitrogen-poor PMM soil type, with no difference in G. boreale biomass found when grown with either competitor. Trends in G. boreale biomass could be due to a more aggressive competitive strategy and the larger size of $G$. boreale's competitors, which both had a higher average size and $V$. americana was more efficient with water. The decreased biomass of $G$. boreale, when grown with $V$. americana, was unexpected considering that these species are often found growing together in mixed forest understories across Canada (Harper and Macdonald 2001).

\section{Conclusions}

As with all greenhouse studies, there are limitations with applying the results to field situations. However, in terms of understory species establishment, it appears that $V$. americana is a good candidate species for establishing on low resource soils, such as PMM, and may be able to outcompete non-native invaders in these situations. G. boreale, on the other hand, has a much lower growth potential from seed, particularly on low resource soils, but it may be a viable option for establishing on higher resource soils, such as FFMM. However, further studies over multiple growing seasons are needed to confirm this. For the reclamation soil types studied, FFMM and PMM had differing plant growth potentials, but operationally, the use of FFMM is limited by availability. Therefore, the layered soil type might be a good alternative for maintaining plant growth and survival while preserving the limited FFMM soil. Given the increase in $M$. perforata growth with fertilization, care should be taken when fertilizing to ensure that, if fertilizer is applied, it is site and soil specific and is done to benefit desirable native species and not undesirable non-native species.

\section{Abbreviations \\ Al: Aluminum; ANOVA: Analysis of variance; B: Boron; Ca: Calcium; Cd: Cadmium; Cu: Copper; EC: Electrical conductivity; Fe: Iron; FFMM: Forest floor-mineral mix; K: Potassium; Mg: Magnesium; Mn: Manganese; P: Phosphorous; Pb: Lead; PMM: Peat-mineral mix; PRS: Plant root simulator; S: Sulfur; TDR: Time-domain reflectometer; Zn: Zinc}

\section{Acknowledgements}

We thank Edith Li, Ruth Errington, Stephanie Jean, and Shelby Feniak for the help in the greenhouse and Ruth Errington for reviewing an earlier version of this manuscript.

\section{Funding}

This study was funded by Canadian Natural Resources Limited.

\section{Authors' contributions}

$\mathrm{JB}, \mathrm{KS}$, and BP conceived and designed the experiment. JB and KS performed the experiment and analyzed the data. JB, KS, and BP wrote and edited the manuscript. All authors read and approved the final manuscript.

\section{Competing interests}

The authors declare that they have no competing interests.

\section{Publisher's Note}

Springer Nature remains neutral with regard to jurisdictional claims in published maps and institutional affiliations.

Received: 29 June 2017 Accepted: 20 February 2018

Published online: 29 March 2018

$$
\begin{aligned}
& \text { References } \\
& \text { Aerts R (1999) Interspecific competition in natural plant communities: } \\
& \text { mechanisms, trade-offs and plant-soil feedbacks. J Exp Bot 50(330):29-37 } \\
& \text { Buckley YM, Catford J (2016) Does the biogeographic origin of species matter? } \\
& \text { Ecological effects of native and non-native species and the use of origin to } \\
& \text { guide management. J Ecol 104(1):4-17 } \\
& \text { Canham CD, Berkowitz AR, Kelly VR, Lovett GM, Ollinger SV, Schnurr J (1996) } \\
& \text { Biomass allocation and multiple resource limitation in tree seedlings. Can J } \\
& \text { For Res 26(9):1521-1530 } \\
& \text { Chapin FS, Bloom AJ, Field CB, Waring RH (1987) Plant responses to multiple } \\
& \quad \text { environmental factors. Bioscience 37(1):49-57 } \\
& \text { Damgaard C, Weiner J (2017) It's about time: a critique of macroecological } \\
& \text { inferences concerning plant competition. Trends Ecol Evol 32(2):86-87 } \\
& \text { DeMalach N, Zaady E, Weiner J, Kadmon R (2016) Size asymmetry of resource } \\
& \text { competition and the structure of plant communities. J Ecol 104(4):899-910 }
\end{aligned}
$$


Duan M, House J, Chang SX (2015) Limiting factors for lodgepole pine (Pinus contorta) and white spruce (Picea glauca) growth differ in some reconstructed sites in the Athabasca oil sands region. Ecol Eng 75(2015):323-331

Errington RC, Pinno BD (2016) Earlier successional plant community dynamics on a reclaimed oil sands min in comparison with natural boreal forest communities. Écoscience 22(2-4):133-144

Franklin JA, Zipper CE, Burger JA, Skousen JG, Jacobs DF (2012) Influence of herbaceous ground cover on forest restoration of eastern US coal surface mines. New For 43:905-924

Fridley JD (2002) Resource availability dominates and alters the relationship between species diversity and ecosystem productivity in experimental plant communities. Oecologia 132(2):271-277

Gallacher AE, Sprent JI (1978) The effect of different water regimes on growth and nodule development of greenhouse-grown Vicia faba. J Exp Bot 29(2):413-423

Haffani S, Mezni M, Slama I, Ksontini M, Chaibi W (2014) Plant growth, water relations and proline content of three vetch species under water-limited conditions. Grass Forage Sci 69(2):323-333

Harper K, Macdonald S (2001) Structure and composition of riparian boreal Forest: new methods for analyzing edge influence. Ecology 82(3):649-659

Huenneke LF, Hamburg SP, Koide R, Mooney HA, Vitousek PM (1990) Effects of soil resources on plant invasion and community structure in Californian serpentine grassland. Ecology 71(2):478-491

Kim DS, Marshall EJP, Caseley JC, Brain P (2006) Modelling interactions between herbicide and nitrogen fertiliser in terms of weed response. Weed Res 46(6):480-491

Kurdali F, Sharabi NE, Arslan A (1996) Rainfed vetch-barley mixed cropping in the Syrian semi-arid conditions. Plant Soil 183(1):137-148

Kwak JH, Chang SX, Naeth MA, Schaaf W (2016) Nitrogen transformation rates are affected by cover soil type but not coarse woody debris application in reclaimed oil sands soils. Restor Ecol 24(4):506-516

Li XP, Chang SX, Salifu KF (2014) Soil texture and layering effects on water and salt dynamics in the presence of a water table: a review. Environ Rev 22(1):41-50

MacKenzie MD, Quideau SA (2011) Laboratory-based nitrogen mineralization and biogeochemistry of two soils used in oil sands reclamation. Can J Soil Sci 92(1):131-142

McLean A (1969) Fire resistance of forest species as influenced by root systems. J Range Manag 22:120-122

McMillan R, Quideau SA, MacKenzie MD, Biryukova O (2007) Nitrogen mineralization and microbial activity in oil sands reclaimed boreal forest soils. J Environ Qual 36(5):1470-1478

Paul EA, Myers RJ, Rice WA (1971) Nitrogen fixation in grassland and associated cultivated ecosystems. Plant Soil 35(1):495-507

Pinno BD, Errington RC (2015) Maximizing natural trembling aspen seedling establishment on a reclaimed boreal oil sands site. Ecol Rest 33(1):43-50

Pinno BD, Landhäusser SM, Chow PS, Quideau SA, MacKenzie MD (2013) Nutrient uptake and growth of fireweed (Chamerion angustifolium) on reclamation soils. Can J For Res 44(1):1-7

Pyšek P, Lepš J (1991) Response of a weed community to nitrogen fertilization: a multivariate analysis. J Veg Sci 2(2):237-244

Rochester IJ, Peoples MB, Constable GA, Gault RR (1998) Faba beans and other legumes add nitrogen to irrigated cotton cropping systems. Anim Prod Sci 38(3):253-260

Schott KM, Snively AE, Landhäusser SM, Pinno BD (2016) Nutrient loaded seedlings reduce the need for field fertilization and vegetation management on boreal forest reclamation sites. New For 47(3):393-410

Sloan JL, Jacobs DF (2013) Fertilization at planting influences seedling growth and vegetative competition on a post-mining boreal reclamation site. New For 44(5):687-701

Staples TE, Van Rees KC, Kessel CV (1999) Nitrogen competition using ${ }^{15} \mathrm{~N}$ between early successional plants and planted white spruce seedlings. Can J For Res 29(8):1282-1289

Tosti G, Benincasa P, Guiducci M (2010) Competition and facilitation in hairy vetch-barley intercrops. Ital J Agro 5(3):239-248

Wilson SD, Pinno BD (2013) Environmentally-contingent behaviour of grassland plants as drivers or passengers. Oikos 122(1):129-135

Wilson SD, Tilman D (1991) Component of plant competition along an experimental gradient of nitrogen availability. Ecology 72(3):1050-1065

Woo SL, Harms VL, Thomas AG, Peschken DP, Bowes GG, Douglas DW, McClay AS (1991) The biology of Canadian weeds. 99. Matricaria perforata Merat (Asteraceae). Can J Plant Sci 71(4):1101-1119

Zettl JD, Barbour SL, Huang M, Si BC, Leskiw LA (2011) Influence of textural layering on field capacity of coarse soils. Can J Soil Sci 91(2):133-147

\section{Submit your manuscript to a SpringerOpen ${ }^{\circ}$ journal and benefit from:}

- Convenient online submission

- Rigorous peer review

- Open access: articles freely available online

- High visibility within the field

- Retaining the copyright to your article

Submit your next manuscript at $\boldsymbol{\wedge}$ springeropen.com 